\title{
Efectos de la retroactividad en materia de ineficacia de los actos jurídicos
}

\section{Lizardo Taboada Córdova}

Los negocios jurídicos, que en nuestro Código civil son denominados "actos jurídicos", constituyen sin lugar a dudas la especie más importante de hechos jurídicos voluntarios, por cuanto a través de ellos los particulares tienen la posibilidad de satisfacer las múltiples y variadas necesidades en su vida de relación con otros sujetos de derecho. No debe olvidarse sin embargo, que los negocios jurídicos, para ser caracterizados y tutelados como tales, deben estar orientados al logro de funciones socialmente razonables y dignas. Además de ello, los negocios jurídicos deben tener un contenido perfectamente lícito, que no atente contra el orden público, las buenas costumbres, ni las normas imperativas. Por ello, debe quedar claramente establecido que los negocios jurídicos son celebrados para que produzcan válidamente efectos jurídicos, pues si no se llegaran a producir los efectos jurídicos, buscados por los sujetos como simples efectos prácticos, no tendría sentido alguno que los sujetos celebraran negocios jurídicos.

Queda evidenciada pues la importancia de la producción de los efectos jurídicos tanto en el campo de los negocios jurídicos como de los contratos, pues lo que distingue un negocio jurídico y contrato válidamente celebrado y eficaz de otro que no lo es, es justamente la producción de los efectos jurídicos, bien se trate de la creación, modificación, regulación o extinción de relaciones jurídicas patrimoniales o extrapatrimoniales. Esto significa entonces que los negocios jurídicos y contratos se celebran para ser eficaces, por cuanto en tanto lo sean, permitirán que los sujetos autorregulen sus intereses privados satisfaciendo sus más variadas y diferentes necesidades. 
Sin embargo, sucede en muchos casos que los negocios jurídicos y contratos no son eficaces, pues no llegan en ningún caso a producir efectos jurídicos, o porque los efectos jurídicos que se han producido inicialmente llegan a desaparecer por un evento posterior a la celebración de los mismos. Bajo estos supuestos estamos dentro de lo que se denomina en doctrina «ineficacia» del negocio jurídico o del contrato. Consiguientemente, la categoría genérica que describe todos los supuestos en los cuales los negocios jurídicos y contratos no son eficaces, por no haber producido nunca efectos jurídicos, o por desaparecer posteriormente los efectos jurídicos producidos inicialmente, recibe el nombre genérico de ineficacia. Las razones de la ineficacia son distintas, pero en términos genéricos la ineficacia bien sea esta inicial, o sobreviniente, es consecuencia por regla general del incumplimiento de un requisito de orden legal, bien sea al momento de la celebración del negocio jurídico, o con posterioridad a la misma, que justifique que no se produzcan nunca los efectos jurídicos deseados, o que los efectos jurídicos ya producidos desaparezcan. Sin embargo, por excepción, en algunos casos de ineficacia sobreviniente, la misma puede ser consecuencia no del incumplimiento de un requisito de orden legal, sino de la voluntad de las mismas partes, como sucede en los supuestos de resolución voluntaria. Esto significa que las partes en aplicación del principio de autonomía privada pueden disponer que un negocio jurídico o contrato libremente celebrado por ellas, que ha venido produciendo normal y válidamente todos sus efectos jurídicos, deje de producirlos por resolución voluntaria. Pero, en términos generales, la ineficacia sea inicial o sobreviniente, es siempre producto del incumplimiento de un requisito o aspecto de orden legal.

La ineficacia estructural es aquella que se presenta al momento mismo de la celebración del negocio jurídico, es decir, se trata de un negocio jurídico afectado por una causal de ineficacia desde el momento mismo de su celebración o formación. Sin embargo, no basta que se trate de una causal de ineficacia que se presente al momento de la formación, sino que además de ello es necesario que la causal suponga un defecto en la estructura del negocio jurídico. En otros términos, todos los supuestos de ineficacia estructural, como su propio nombre lo indica claramente, suponen un negocio jurídico mal formado, mal estructurado, con un defecto congénito, de modo tal que se trate de un negocio jurídico con un defecto intrínseco. Debe recordarse que en los 
casos de rescisión, que es uno de los supuestos de ineficacia funcional, la causal también es coetánea a la celebración del negocio, pero totalmente ajena a un defecto en su estructura, razón por la cual no se puede confundir la rescisión con los supuestos de ineficacia estructural o invalidez. En tercer lugar, como nota distintiva de la ineficacia estructural o invalidez, debemos señalar que la misma se fundamenta exclusivamente en el principio de legalidad, pues todas las causales de invalidez vienen siempre establecidas por la ley, no puede ser consecuencia del pacto entre las partes. Vale decir, la invalidez no puede ser pactada, no puede ser acordada por las partes que han celebrado un negocio jurídico.

Ahora bien, por el contrario, la ineficacia funcional, a diferencia de la ineficacia estructural o invalidez, supone en todos los casos, un negocio jurídico perfectamente estructurado, en el cual han concurrido todos sus elementos, presupuestos y requisitos de orden legal, sólo que dicho negocio jurídico por un evento ajeno a su estructura debe dejar de producir efectos jurídicos. Y es por ello que se dice que en los supuestos de ineficacia funcional, los negocios jurídicos tienen también un defecto, pero totalmente ajeno a su estructura, no intrínseca, sino extrínseco. Esto significa en consecuencia, que los negocios jurídicos atacados o afectados por causales de ineficacia funcional o sobreviniente, son negocios jurídicos perfectamente bien estructurados y conformados, pues el defecto que se presenta posteriormente es totalmente extraño a la conformación estructural del negocio jurídico.

Del mismo modo, en los supuestos de ineficacia funcional, a diferencia de los supuestos de invalidez, por regla general el defecto se presenta con posterioridad a la celebración o formación del negocio jurídico y es por ello que se habla de ineficacia funcional o sobreviniente, para marcar la diferencia respecto de la ineficacia estructural o invalidez. Sin embargo, esta segunda nota distintiva de la ineficacia funcional no es absoluta, pues no se presenta en todos los supuestos de dicha ineficacia, pues como ya lo hemos mencionado en los casos de rescisión, que es uno de los supuestos de ineficacia funcional, la causa de ineficacia es coetánea a la formación del negocio jurídico. Sin embargo, en la generalidad de los casos, las causales de ineficacia funcional son siempre sobrevinientes a la formación de los negocios jurídicos. Finalmente, a diferencia de la ineficacia estructural, en algunos casos la ineficacia funcional puede ser consecuencia del pacto entre las partes 
que han celebrado un negocio jurídico. Se pueden pactar libremente por las partes las causales de ineficacia funcional, en aplicación del principio de autonomía privada, que es el principio directriz en materia de negocios jurídicos y contratos.

Al ser la nulidad y la anulabilidad las únicas categorías de invalidez o ineficacia estructural, resulta claro que las notas comunes a ambas figuras son las tres que caracterizan a la invalidez por contraposición a la ineficacia funcional, es decir, en ambos casos, tanto en los supuestos de nulidad como de anulabilidad, las causales son siempre coetáneas a la celebración del negocio jurídico, estando siempre referidas a un defecto en la estructura del negocio jurídico, no pudiendo en ningún caso ser pactadas pues vienen siempre establecidas por la ley. Sin embargo, existen diferencias muy importantes entre las dos categorías, consecuencia del diferente grado de gravedad que supone la nulidad respecto de la anulabilidad. Así pues la acción para solicitar la declaración judicial de nulidad de un negocio jurídico puede ser interpuesta no sólo por cualquiera de las partes que lo han celebrado, sino también por cualquier tercero, siempre que acredite legítimo interés económico o moral, o por el Ministerio Público. Incluso el juez puede declarar de oficio una nulidad cuando la misma resulte manifiesta, según lo establece claramente el artículo $220^{\circ}$ del Código civil peruano.

Por el contrario, la acción judicial para solicitar la anulabilidad del negocio jurídico sólo puede ser interpuesta por la parte perjudicada que ha celebrado el negocio jurídico viciado, en cuyo beneficio la ley establece dicha acción. Esta diferencia, como es evidente, es consecuencia de la diferencia de grado de gravedad que existe entre la nulidad y la anulabilidad, según vimos anteriormente. Tal es la gravedad de la nulidad como sanción del sistema jurídico para los negocios jurídicos defectuosamente conformados o cuyo contenido es ilícito, que la acción judicial para que se declare judicialmente la misma puede interponerla cualquier persona, siempre que acredite legítimo interés para ello, pudiendo solicitarla también el Ministerio Público como defensor de la legalidad, o el juez de oficio cuando la misma resulte manifiesta. Por el contrario, como la causal de anulabilidad sólo atenta contra el interés privado, afectando a una de las partes que ha celebrado el negocio jurídico, el artículo $222^{\circ}$ del Código civil cuida bien en señalar que la misma se pronunciará a petición de parte y no puede ser alegada por otras personas que aquellas en cuyo beneficio la establece la ley. 
Ahora bien, como lo veremos inmediatamente después, la acción de anulabilidad no tiene como objetivo que se declare la anulabilidad del negocio jurídico atacado por la causal de anulabilidad, sino que se declare la nulidad del negocio anulable, es decir, afectado por la causal de anulabilidad. Los negocios jurídicos anulables pueden ser declarados judicialmente nulos, en ningún caso podrán ser declarados judicialmente anulables. La razón es muy simple: cuando un negocio afectado por causal de anulabilidad es impugnado por la parte afectada por la causal, que no desea confirmarlo, el juez, en caso de acreditarse la misma, deberá declarar la nulidad del negocio anulable, el cual se considerará nulo desde la fecha de su celebración por efecto de la sentencia que lo declare.

Sin embargo, la diferencia fundamental entre ambas categorías radica en que los actos nulos nacen muertos y por ende no producen ninguno de los efectos jurídicos que tendrían que haber producido. Por el contrario, los actos anulables nacen con vida, pero gravemente enfermos y como tales tienen un doble destino alternativo y excluyente: o son subsanados o convalidados a través de la confirmación, o son declarados judicialmente nulos a través de la acción de anulabilidad. Respecto de los negocios anulables, debemos decir, que a diferencia de los negocios nulos, los mismos nacen produciendo todos sus efectos jurídicos, y los seguirán produciendo normalmente si son confirmados, o dejaran de producirlos si son declarados judicialmente nulos.

Conviene insistir, mientras el negocio nulo nace muerto y por ende en ningún momento produce ninguno de los efectos jurídicos que tendría que haber producido, por haber nacido sin vida, los negocios anulables por el contrario nacen enfermos pero con vida, y por ende produciendo todos sus efectos jurídicos, pero los dejará de producir en caso la parte afectada por la causal de anulabilidad opte por solicitar judicialmente la nulidad del mismo, o los seguirá produciendo normalmente en caso la parte afectada opte por confirmar el acto, es decir, por subsanar el vicio que lo afectaba. Esto significa en consecuencia que el doble destino alternativo y excluyente del negocio anulable depende de la parte afectada por la causal de anulabilidad, que es quien decide la suerte del acto anulable.

A fin de entender el doble destino del acto anulable, es necesario precisar lo siguiente: el objetivo de la acción de anulabilidad, como lo hemos mencionado, no es la declaración judicial de anulabilidad, sino 
la declaración judicial de nulidad del negocio anulable, y esto es así por cuanto una de las posibilidades del negocio anulable es justamente la de ser declarado judicialmente nulo como consecuencia de la acción de anulabilidad, previa acreditación de la causal evidentemente.

Ahora bien, como ya hemos indicado, en los casos de negocios anulables confirmados, los efectos jurídicos que ha venido produciendo el acto desde su nacimiento, los seguirá produciendo normalmente justamente por haberse subsanado el vicio que lo afectaba. Por el contrario, en el caso de negocios anulables declarados judicialmente nulos por interposición de la acción de anulabilidad, los efectos que el acto anulable produjo desde su nacimiento, desaparecerán como consecuencia de la sentencia firme que declare la nulidad del negocio anulable. Pero los efectos no desaparecen desde la fecha de expedición de la sentencia hacia delante, sino retroactivamente a la fecha de celebración del negocio jurídico, de modo tal que el acto anulable declarado judicialmente nulo es como si hubiera sido nulo desde siempre, como consecuencia del efecto retroactivo de la sentencia. Esta retroactividad del efecto jurídico, denominada retroactividad obligacional, viene establecida en forma clara por el artículo $222^{\circ}$ del Código civil, cuando dispone que el acto jurídico anulable es nulo desde su celebración, por efecto de la sentencia que lo declare.

De esta forma se entiende, ahora sí, con claridad el doble destino alternativo del negocio anulable, el cual precisamos de la siguiente manera: el acto anulable nace con vida produciendo todos sus efectos jurídicos, pero por haber nacido con una enfermedad grave tiene un doble destino alternativo y excluyente: $o$ es subsanado o convalidado por la confirmación en cuyo caso seguirá produciendo normalmente todos sus efectos jurídicos, o por el contrario es declarado judicialmente nulo como consecuencia de la interposición de la acción de anulabilidad, en cuyo caso los efectos jurídicos que produjo desaparecerán retroactivamente a la fecha de celebración del acto. Como es evidente, para poder entender a profundidad esta diferencia ha sido necesario precisar el objetivo de la acción de anulabilidad y el efecto retroactivo de la sentencia que declara la nulidad del acto anulable. Por el contrario, el acto nulo nace sin vida y en ningún caso puede producir ninguno de los efectos jurídicos que tendría que haber producido.

La nulidad opera de pleno derecho, siendo por tanto la sentencia que declare judicialmente la nulidad de un acto afectado por causal de 
nulidad, meramente declarativa, al limitarse a constatar que se presentó y operó la causal de nulidad y que el negocio jurídico nació muerto sin producir ninguno de sus efectos jurídicos. Por el contrario, la sentencia que declara judicialmente la nulidad de un negocio jurídico atacado por una causal de anulabilidad no es declarativa, sino constitutiva, por cuanto la nulidad del acto anulable no opera ipso iure o de pleno derecho, sino que se constituye recién por la sentencia que la declara. Sobre este aspecto que es fundamental para entender cabalmente la diferencia entre nulidad y anulabilidad, debe precisarse lo siguiente: si bien es cierto que la nulidad opera de pleno derecho, sin necesidad de sentencia alguna, es conveniente para efectos prácticos contar con una sentencia que declare judicialmente la nulidad, a fin de tutelar fundamentalmente a los terceros de la apariencia de validez de un acto nulo. Por el contrario, la única forma en que un acto anulable será considerado nulo desde la fecha de su celebración es por efecto de la sentencia que declare dicha nulidad y es por ello que se dice que en materia de anulabilidad la sentencia que declara su nulidad es constitutiva.

Pues bien, habiendo precisado la diferencia fundamental que existe entre la nulidad y la anulabilidad respecto de sus efectos, debemos ahora precisar si los terceros que hubieren adquirido aparentemente derechos de la celebración de un acto nulo, se encuentran o no protegidos legalmente en el sistema jurídico peruano. Es decir, sabiendo ya que los actos nulos son aquellos que nunca producen efectos jurídicos, pues nacen muertos, debemos preguntarnos sobre la situación de los terceros que hubieren adquirido derechos aparentemente derivados de la celebración de un acto jurídico nulo por estar afectado por una causal de nulidad. En efecto, si se dice y como sucede en efecto en el ordenamiento jurídico peruano, que los actos nulos no producen ninguno de los efectos jurídicos que tendrían que haber producido, resultara evidente por consecuencia lógica que los actos nulos no producen efectos jurídicos de ninguna clase, tanto entre las partes como respecto de los terceros. En otras palabras, nadie, ni las partes ni ningún tercero podrían reclamar un derecho como consecuencia de la celebración de un acto jurídico nulo, por la simple razón que los actos nulos han nacido muertos, sin producir ninguno de sus efectos jurídicos. Consiguientemente las partes no quedarán vinculadas legalmente, y por ende ningún tercero podrá reclamar un derecho derivado de la celebración de dicho acto jurídico. 
Sin embargo, el Código civil peruano no se pronuncia sobre este aspecto, es decir, no existe ninguna norma jurídica que establezca si los terceros pueden o no derivar algún derecho como consecuencia de la celebración de los actos afectados por una causal de nulidad, de aquellas contempladas en el artículo $219^{\circ} \mathrm{del}$ mismo Código civil. En efecto, el artículo $220^{\circ}$ se limita a señalar "que la nulidad a que se refiere el articulo $219^{\circ}$ puede ser alegada por quienes tengan interés o por el ministerio publico y que puede ser declarada de oficio por el juez cuando resulte manifiesta. Señalándose finalmente que no puede subsanarse por la confirmación.

No obstante lo cual, podría entenderse que la referencia a este aspecto sobre la protección o no de los terceros en materia de nulidad sería absolutamente innecesaria, en la medida que se sabe que los actos nulos no producen nunca ningún efecto jurídico, ni entre las partes ni respecto de los terceros. En efecto, desde nuestro punto de vista la referencia a la protección de los terceros en materia de nulidad de los actos jurídicos en el Código civil peruano deviene en innecesaria, por cuanto si los actos nulos no producen nunca ninguno de los efectos jurídicos que tendrían que haber producido, resulta evidente que nadie podrá reclamar un derecho derivado de la celebración de un acto jurídico nulo, ni las partes, menos aún los terceros, por mas que hubieren actuado con buena fe. Desde nuestro punto de vista proteger a los terceros en materia de actos nulos, sería una contradicción respecto al enunciado del mismo artículo $220^{\circ}$.

Por ello, desde nuestro punto de vista, los terceros no pueden derivar o reclamar ningún derecho de la celebración de los actos nulos, por cuanto ello implicaría contradecir el principio fundamental en materia de nulidad, según el cual los actos nulos nacen muertos y no pueden producir ningún efecto jurídico. Y es por esta razón que desde nuestro punto de vista no existe ninguna norma que en el Título IX del Libro II del Código civil, dedicado a la nulidad del acto jurídico, permita afirmar que los terceros pueden ser protegidos en materia de nulidad, derivando algún derecho de la celebración de un acto jurídico afectado por una causal de nulidad. En nuestro concepto la lógica del sistema jurídico sobre nulidad de los actos jurídicos es que los mismos no produzcan nunca efectos jurídicos, no mereciendo los terceros ningún tipo de tutela especial. En otros términos, según nuestro punto de vista la posición del Código civil peruano es que los terceros no pueden recla- 
mar o derivar derechos de la celebración de actos jurídicos nulos y es por esa razón que no existe ninguna norma sobre protección de los terceros en esta materia en el Titulo IX dedicado a la nulidad del acto jurídico.

Por esta misma razón, pensamos que no se pueden invocar razones de aplicación de principios generales del derecho en esta materia, o fundamentos en razones de justicia o equidad. Sin embargo, así como pensamos que en materia de nulidad los terceros no se encuentran protegidos, debemos señalar en forma categórica que la no protección de los terceros es la regla general, pues en el propio Código civil, en el mismo Libro II sobre el acto jurídico, en otro título, existe un supuesto específico de protección a los terceros de buena fe en materia de una causal específica de nulidad de los actos jurídicos. Nos referimos al supuesto específico de la nulidad por simulación de los actos jurídicos. Por ello, es necesario desde este momento, examinar el fenómeno de la simulación y su regulación en el Código civil peruano, a fin de abordar la problemática que nos ocupa sobre la protección de los terceros en materia de nulidad de los actos jurídicos. Para ello será necesario referirnos al inciso quinto del artículo $219^{\circ}$ antes mencionado.

Según el inciso 5 del artículo $219^{\circ}$ el acto jurídico será nulo cuando adolezca de simulación absoluta. Como es sabido, para la casi totalidad de los civilistas la simulación no consiste sino en un caso de discrepancia entre la voluntad declarada y la voluntad interna, realizada de común acuerdo entre las partes contratantes, a través del acuerdo simulatorio, con el fin de engañar a los terceros. En forma unánime la doctrina distingue dos clases de simulación: la simulación absoluta en que existe un solo negocio jurídico denominado "simulado", y la simulación relativa en que detrás del negocio simulado permanece oculto un verdadero negocio jurídico que se denomina «disimulado». Tanto en el supuesto de la simulación absoluta como en el de la relativa el negocio jurídico simulado es siempre nulo, por cuanto no contiene la verdadera voluntad de las partes contratantes, mientras que en la simulación relativa el acto disimulado, en la medida en que contenga todos sus requisitos de sustancia y forma, será siempre válido por ser un negocio jurídico verdadero y real que contiene la auténtica voluntad de las partes contratantes.

Siendo esto así, resulta incongruente que el inciso 5 del artículo $219^{\circ}$, sancione con nulidad únicamente al acto jurídico simulado en la 
simulación absoluta, por cuanto como ya lo hemos expresado el negocio jurídico simulado es nulo tanto en la simulación absoluta como en la relativa. El Código civil ha debido señalar únicamente que el acto jurídico será nulo cuando sea simulado, pues de esta forma hubiera quedado perfectamente establecida la nulidad del acto simulado o aparente en cualquier supuesto de simulación.

En la simulación absoluta es claro que nos encontramos frente a un supuesto de nulidad, por no existir voluntad real de las partes de celebrar ningún negocio jurídico, sino únicamente el de aparentar la celebración de uno, según lo dispone claramente el artículo $190^{\circ}$ del Código civil, cuando dice "por la simulación absoluta se aparenta celebrar un acto jurídico cuando no existe realmente voluntad para celebrarlo". Por el contrario, en los supuestos de simulación relativa se celebran dos negocios jurídicos: el simulado o aparente que las partes saben que es falso pues no corresponde a su voluntad real y el disimulado que es verdadero y que las partes han querido celebrar realmente, sólo que ocultándolo a los terceros bajo la fachada del acto simulado o aparente.

Como es evidente, en las hipótesis de simulación relativa el acto simulado es nulo por ser aparente, al no corresponder a la voluntad real de las partes, mientras que el acto disimulado es válido, por ser verdadero y corresponder a la verdadera voluntad de las partes, pero siempre y cuando concurran sus requisitos de sustancia y forma y no se perjudique el derecho de terceros, según lo establece claramente el artículo $191^{\circ}$ del Código civil, cuando señala «cuando las partes han querido concluir un acto distinto del aparente, tiene efecto entre ellas el acto ocultado, siempre que concurran los requisitos de sustancia y forma y no perjudique el derecho de tercer».

Como se podrá comprender, el acto ocultado o acto disimulado por ser verdadero en principio es válido, pero siempre y cuando concurran sus requisitos de sustancia y forma, es decir, siempre y cuando concurran todos los aspectos de su estructura, y es por eso que el artículo $191^{\circ}$ dice "tiene efecto entre ellas". De esta manera, resulta evidente, que en los casos de simulación absoluta, el único acto que han celebrado las partes que es simulado, por no corresponder a su verdadera voluntad, es nulo. Del mismo modo, en el caso de la simulación relativa, el acto simulado o aparente, que las partes usan como fachada para ocultar el acto jurídico verdadero que permanece disimulado y ocultado a los terceros, es también nulo por no corresponder a la vo- 
luntad real de las partes. Por el contrario, el acto ocultado o disimulado, llamado también acto real, por ser verdadero, será válido, siempre y cuando concurran sus requisitos de contenido y formalidad y no se perjudique el derecho de los terceros. En tal sentido, no puede haber duda alguna que en materia de simulación son nulos los actos simulados, bien se trate de la simulación absoluta como de la simulación relativa. Y es por ello, que desde nuestro punto de vista, es incorrecta la referencia que hace el inciso en cuestión únicamente a la simulación absoluta. No debe quedar duda alguna sobre la nulidad de los actos simulados en la simulación relativa, según fluye con total claridad del artículo $191^{\circ}$, que define el fenómeno de la simulación relativa, en la que existen dos actos jurídicos: el simulado y el disimulado.

El mismo Código civil se refiere a la simulación relativa en el artículo $221^{\circ}$ dedicado a las causales de anulabilidad. Pues bien, la causal de anulabilidad contemplada en el tercer inciso del artículo $221^{\circ}$ hace referencia al acto disimulado en los supuestos de simulación relativa, cuando el mismo, reuniendo todos sus requisitos de sustancia y forma, perjudica sin embargo el derecho de tercero. Esto significa en consecuencia que esta causal de anulabilidad sólo está referida al acto disimulado u ocultado, no al acto simulado el cual es nulo por no corresponder a la voluntad real de las partes. Pero se refiere al acto disimulado solamente cuando el mismo perjudica el derecho de tercero, en cuyo caso será anulable. Si el acto disimulado carece de algún requisito de sustancia o formalidad, como cualquier otro negocio jurídico celebrado verdaderamente, será nulo por falta de un aspecto de su estructura. Por lo tanto la causal de anulabilidad que estamos comentando, solamente se refiere al supuesto en el cual el acto disimulado perjudique el derecho de tercero. Es decir, los actos disimulados que en principio son válidos, serán anulables cuando perjudiquen los derechos de los terceros.

Si se observa con atención la norma del tercer inciso en comentario no hace referencia a los actos simulados, sino únicamente a los actos disimulados, que son verdaderos, y en tal sentido la norma no está referida a la protección de los terceros como consecuencia de la celebración de actos nulos, sino a la protección de los terceros como consecuencia de actos válidos que se ocultan bajo actos aparentes o simulados, que es justamente la característica fundamental de la simulación relativa, a diferencia de la simulación absoluta. Sin embargo, existe una 
norma en el mismo Título VI sobre simulación del acto jurídico, que sí hace referencia directa al tema que nos ocupa sobre la protección a los terceros como consecuencia de la celebración de actos jurídicos afectados por causal de nulidad. Nos referimos al artículo $194^{\circ}$ del mismo Código civil, cuyo texto señala lo siguiente: "La simulación no puede ser opuesta por las partes ni por los terceros perjudicados a quien de buena fe y a título oneroso haya adquirido derechos del titular aparente».

En efecto, el artículo $194^{\circ}$ del Código civil tutela en forma directa y específica a los terceros en materia de nulidad por simulación, y es por ello que dice que la simulación no puede ser opuesta por las partes ni por los terceros perjudicados a quien de buena fe y a título oneroso hubiere adquirido derechos del titular aparente. Sin embargo, se trata de un supuesto específico de protección de los terceros para la causal de nulidad referida a la simulación, y no así para las otras causales de nulidad contempladas en el artículo $219^{\circ}$ del Código civil. Más aún, se exige que el tercero hubiere actuado a título oneroso y con buena fe, pues caso contrario el tercero no será protegido y no podrá conservar ningún derecho que hubiere adquirido del titular aparente.

Hace bien el Código civil cuando se refiere al titular aparente, pues como ya hemos visto los actos nulos no producen ningún efecto jurídico y por ende no existe titular de ninguna clase. Sin embargo, en el caso particular de la simulación, los titulares de derechos serán aparentes, pues no se olvide que el objetivo de la simulación es aparentar o hacer creer a los terceros que los actos jurídicos simulados, son verdaderos y por ende han producido efectos jurídicos. En tal sentido, está plenamente justificada la expresión titular aparente.

Si se observa bien, en este caso particular, la protección al tercero de buena fe que actúa a título oneroso, es consecuencia de que el tercero ha confiado en la apariencia creada por las partes que han celebrado el acto jurídico simulado y en tal sentido sería totalmente injusto no proteger a los terceros que por haber confiado han creído en la apariencia. Sin embargo, la lógica de esta especial protección a los terceros no es una regla general, sino que se fundamenta en la necesidad de tutelar las apariencias cuando los terceros han confiado en ellas por haber actuado de buena fe.

Ahora bien, desde nuestro punto de vista, la protección que se le concede al tercero en el supuesto especial de la simulación, es una regla 
excepcional, que demuestra que la regla general es justamente la no protección de los terceros, aún cuando hubieren actuado de buena fe.

No podemos interpretar el artículo $194^{\circ}$ como referido a una regla general de protección de los terceros de buena fe a título oneroso en cualquier supuesto de causal de nulidad de los actos jurídicos. Pensamos que si la intención del legislador hubiera sido tutelar al tercero en todos los casos, ello se hubiera consagrado como regla general en algún artículo del Código civil. Sin embargo, en el artículo $220^{\circ}$ que establece las características de los actos nulos, no se hace ninguna referencia a la protección de los terceros como regla general para cualquier causal de nulidad. Solamente existe el artículo $194^{\circ}$ para el caso particular de la simulación, fundamentado en la necesidad de proteger a los terceros que han confiado en las apariencias, cuando la intención de las partes contratantes es el celebrar un acto jurídico aparente, a fin de engañar a los terceros, en cuyo caso no se encuentra justificado dejarlos sin protección, cuando por haber actuado de buena fe han confiado en la apariencia. Esta regla especial es pues una aplicación de la teoría de la confianza en materia de simulación de los actos jurídicos. Sin embargo, insistimos, no se puede interpretar por extensión o en forma analógica como referida a cualquier otra causal de nulidad de los actos jurídicos.

Ahora bien, en el caso de los actos anulables declarados judicialmente nulos por haber interpuesto la parte perjudicada por la causal de anulabilidad, la acción de anulabilidad, la situación es exactamente la misma. No existe en el Código civil peruano ninguna norma que haga referencia a una protección a los terceros de buena fe y a título oneroso. Por el contrario el artículo $222^{\circ}$ que establece las características de los actos anulables se limita a decir que el acto jurídico anulable es nulo desde su celebración, por efecto de la sentencia que lo declare. Y que esta nulidad se pronunciará a petición de parte y no puede ser alegada por otras personas que aquellas en cuyo beneficio la establece la ley.

Como ya lo hemos comentado anteriormente, la diferencia fundamental entre la nulidad y la anulabilidad radica en que los actos nulos nacen muertos y por ende no producen ninguno de los efectos jurídicos que tendrían que haber producido. Por el contrario, los actos anulables nacen con vida, pero gravemente enfermos y como tales tienen un doble destino alternativo y excluyente: o son subsanados o convalidados a través de la confirmación, o son declarados judicialmente nulos a través de la acción de anulabilidad. Los negocios anulables, 
debemos decir, que a diferencia de los negocios nulos, los mismos nacen produciendo todos sus efectos jurídicos, y los seguirán produciendo normalmente si son confirmados, o dejarán de producirlos si son declarados judicialmente nulos.

Conviene insistir, mientras el negocio nulo nace muerto y por ende en ningún momento produce ninguno de los efectos jurídicos que tendría que haber producido, por haber nacido sin vida, los negocios anulables por el contrario nacen enfermos pero con vida, y por ende produciendo todos sus efectos jurídicos, pero los dejará de producir en caso la parte afectada por la causal de anulabilidad opte por solicitar judicialmente la nulidad del mismo, o los seguirá produciendo normalmente en caso la parte afectada opte por confirmar el acto, es decir, por subsanar el vicio que lo afectaba. Esto significa en consecuencia, que el doble destino alternativo y excluyente del negocio anulable depende de la parte afectada por la causal de anulabilidad, que es quien decide la suerte del acto anulable.

A fin de entender el doble destino del acto anulable, es necesario precisar lo siguiente: el objetivo de la acción de anulabilidad, como lo hemos mencionado, no es la declaración judicial de anulabilidad, sino la declaración judicial de nulidad del negocio anulable, y esto es así por cuanto una de las posibilidades del negocio anulable es justamente la de ser declarado judicialmente nulo como consecuencia de la acción de anulabilidad, previa acreditación de la causal evidentemente.

Ahora bien, como ya hemos indicado, en los casos de negocios anulables confirmados, los efectos jurídicos que ha venido produciendo el acto desde su nacimiento, los seguirá produciendo normalmente justamente por haberse subsanado el vicio que lo afectaba.

Por el contrario, en el caso de negocios anulables declarados judicialmente nulos por interposición de la acción de anulabilidad, los efectos que el acto anulable produjo desde su nacimiento, desaparecerán como consecuencia de la sentencia firme que declare la nulidad del negocio anulable. Pero los efectos no desaparecen desde la fecha de expedición de la sentencia hacia delante, sino retroactivamente a la fecha de celebración del negocio jurídico, de modo tal que el acto anulable declarado judicialmente nulo es como si hubiera sido nulo desde siempre, como consecuencia del efecto retroactivo de la sentencia. Esta retroactividad del efecto jurídico, denominada retroactividad obligacional, viene establecida en forma clara por el artículo $222^{\circ}$ del 
Código civil, cuando dispone que el acto jurídico anulable es nulo desde su celebración, por efecto de la sentencia que lo declare.

De esta forma se entiende, ahora sí, con claridad, el doble destino alternativo del negocio anulable, el cual precisamos de la siguiente manera: el acto anulable nace con vida produciendo todos sus efectos jurídicos, pero por haber nacido con una enfermedad grave tiene un doble destino alternativo y excluyente: o es subsanado o convalidado por la confirmación en cuyo caso seguirá produciendo normalmente todos sus efectos jurídicos, o por el contrario es declarado judicialmente nulo como consecuencia de la interposición de la acción de anulabilidad, en cuyo caso los efectos jurídicos que produjo desaparecerán retroactivamente a la fecha de celebración del acto.

Ahora bien, como en el caso específico de los actos anulables declarados judicialmente nulos, los efectos jurídicos se han producido normalmente desde la fecha misma de celebración del acto jurídico, desapareciendo luego posteriormente como consecuencia del efecto retroactivo de la sentencia que declaró su nulidad, resulta más problemático el tema de la protección de los derechos de los terceros de buena fe y a título oneroso. En efecto, en el caso de los actos afectados por causal de nulidad, es claro y evidente que el acto nunca llegó a producir efectos jurídicos ni entre las partes, ni respecto de los terceros. Sin embargo, en el caso de los actos afectados por causal de anulabilidad, los mismos desde la fecha de su celebración, han producido la totalidad de sus efectos jurídicos, y los han continuado produciendo hasta el momento mismo que se hubiera expedido la sentencia consentida o ejecutoriada que declaró la nulidad del acto anulable. Como es evidente, en estos casos, la problemática sobre la tutela de los terceros es más significativa desde el momento mismo que el acto ha producido todos sus efectos jurídicos, en cuyo caso los terceros habrían adquirido o derivado derechos de titulares legítimos, perfectamente justificados, no de titulares inexistentes o aparentes. Pero sin embargo, una vez declarada judicialmente la nulidad del acto anulable, como la misma opera retroactivamente a la fecha de celebración del acto anulable, en vista que el artículo $222^{\circ}$ señala en forma enfática que el acto anulable es nulo desde la fecha de su celebración por efecto de la sentencia que lo declare, jurídicamente los efectos jurídicos producidos normalmente desaparecerían también retroactivamente por el efecto retroactivo de la sentencia que declaró la nulidad. En este sentido, los terceros estarían 
siendo desprotegidos, a pesar de haber estado legitimados en un primer momento por haber derivado o adquirido derechos del titular legítimo.

Sin embargo, el artículo $222^{\circ}$ no contiene ninguna referencia a la protección de los terceros de buena fe y a título oneroso, limitándose a señalar que el acto anulable es nulo desde su celebración por efecto de la sentencia que lo declare. Desde nuestro punto de vista, al decirse que el acto anulable es nulo desde su celebración, se está diciendo que los efectos jurídicos producidos, desaparecen también, como si nunca se hubieran producido. en nuestro concepto, la protección del tercero, en este caso especifico, implicaría también una contradicción con el sistema del Código civil peruano, que ha consagrado la fórmula legal según la cual los actos anulables son nulos desde la fecha de su celebración. Lo que significa que los actos anulables, una vez que han sido declarados judicialmente nulos, no deben tampoco producir ningún efecto jurídico, como sucede con los actos nulos de pleno derecho por estar atacados por una causal de nulidad del artículo $219^{\circ}$. En otras palabras, si los actos anulables son nulos desde la fecha de su celebración, no pueden haber producido nunca efectos jurídicos válidos, y todos los que hubieran producido hasta el momento mismo de la declaración judicial de nulidad, deben desaparecer retroactivamente, es decir, debe entenderse que nunca existieron. Como es evidente, esta regla que identifica los efectos de los actos nulos con aquellos de los actos anulables declarados judicialmente nulos, implica igualmente la no protección de los derechos de los terceros, como sucede en el caso de los actos nulos, a pesar que los terceros inicialmente adquirieron derechos legítimamente de sus titulares legítimos.

Por todo lo expuesto, resulta claro que no se puede afirmar que el sistema jurídico peruano tutele los derechos de los terceros en materia de nulidad y de anulabilidad, pues el sistema apunta a que los actos nulos nunca puedan producir efectos jurídicos y a que los actos anulables se consideren nulos desde la fecha de su celebración por efecto de la sentencia que declare su nulidad. No existe ninguna regla legal que autorice esta protección a los terceros en materia de ineficacia estructural. La regla del artículo $194^{\circ}$ del Código civil sólo se aplica al supuesto de la nulidad por simulación y no se puede aplicar por extensión o por analogía a ningún otro supuesto de nulidad, menos aun a los supuestos de anulabilidad. 
Evidentemente, nuestro punto de vista se basa en la regulación actual del Código civil peruano. Sin embargo, pensamos que en materia de anulabilidad, lo más justo sería tutelar a los terceros de buena fe y a título oneroso y en tal sentido pensamos que el Código civil actual en este punto debe ser modificado.

Por el contrario, en materia de ineficacia funcional, en el caso específico de resolución y rescisión, los derechos de los terceros son protegidos por disposición expresa de la ley, según lo establece el artículo $1372^{\circ}$ del Código civil en forma categórica y rotunda.

De esta manera, llegamos a una diferencia adicional entre las categorías de la ineficacia funcional y la ineficacia estructural o invalidez, que enunciamos finalmente de la siguiente manera: en materia de invalidez no se protege el derecho de los terceros de buena fe, salvo el caso específico de la simulación según lo dispone claramente el artículo $194^{\circ}$. Por el contrario en materia de ineficacia funcional, en los casos más importantes y específicos de resolución y rescisión, se protege por expresa disposición de la ley los derechos de los terceros adquiridos de buena fe. Mas aún, esta protección expresa y directa a los terceros de buena fe en el caso de la ineficacia funcional, nos demuestra claramente que esa protección no existe como regla general para los supuestos de ineficacia estructural, por cuanto la protección a los terceros por razones de seguridad jurídica, exige siempre una disposición legal, no pudiendo invocarse por razones de justicia o equidad principios generales del derecho. Por ser la tutela de los terceros un tema de trascendental importancia exige siempre una expresa disposición legal, como presenta nuestro Código civil en materia de simulación, de resolución y de rescisión. Esta protección del derecho de los terceros que requiere siempre una expresa disposición legal se manifiesta también en otras normas tales como el $1313^{\circ}$, referido a la resolución voluntaria de común acuerdo, llamada mutuo disenso y en el caso especifico del fraude del acto jurídico, según lo prescribe el artículo $197^{\circ}$, cuando señala que la declaración de ineficacia del acto como consecuencia de la acción pauliana o revocatoria no perjudica los derechos adquiridos a título oneroso por los terceros subadquirentes de buena fe.

En conclusión, la protección al tercero de buena fe y a título oneroso, requiere siempre de una expresa disposición legal, y se plantea en el sistema jurídico nacional solo en el caso específico de los supuestos de ineficacia funcional, no así en los supuestos de ineficacia estructural o invalidez, salvo el caso particular de la simulación. 